\title{
Systematic literature review of patient-reported outcome measures used in assessment and measurement of sleep disorders in chronic obstructive pulmonary disease
}

\author{
This article was published in the following Dove Press journal: \\ International Journal of COPD \\ 9 February 2015 \\ Number of times this article has been viewed
}

\section{Adam P Garrow ${ }^{1,2}$ \\ Janelle Yorke ${ }^{2}$ \\ Naimat Khan' \\ Jørgen Vestbo ${ }^{3}$ \\ Dave Singh' \\ Sarah Tyson'}

'University of Manchester Medicines Evaluation Unit, University Hospital of South Manchester Foundation Trust, ${ }^{2}$ School of Nursing, Midwifery and Social Work, University of Manchester, ${ }^{3}$ The University of Manchester Academic Health Science Centre, University Hospital South Manchester NHS Foundation Trust, Manchester, UK
Correspondence: Janelle Yorke School of Nursing, Midwifery and Social Work, University of Manchester, Room 5.320, Jean McFarlane University, University Place, Oxford Road,

Manchester, MI3 9PL, UK

Tel +44 I6I 3067780

Email janelle.yorke@manchester.ac.uk
Background: Sleep problems are common in patients with chronic obstructive pulmonary disease (COPD), but the validity of patient-reported outcome measures (PROMs) that measure sleep dysfunction has not been evaluated. We have reviewed the literature to identify diseasespecific and non-disease-specific sleep PROMs that have been validated for use in COPD patients. The review also examined the psychometric properties of identified sleep outcome measures and extracted point and variability estimates of sleep instruments used in COPD studies.

Methods: The online EMBASE, MEDLINE, PsycINFO, and SCOPUS databases for all years to May 2014 were used to source articles for the review. The review was performed according to Preferred Reporting Items for Systematic Reviews and Meta-Analyses guidelines. Criteria from the Medical Outcomes Trust Scientific Advisory Committee guidelines were used to evaluate the psychometric properties of all sleep PROMs identified.

Results: One COPD-specific and six non-COPD-specific sleep outcome measures were identified and 44 papers met the review selection criteria. We only identified one instrument, the COPD and Asthma Sleep Impact Scale, which was developed specifically for use in COPD populations. Ninety percent of the identified studies used one of two non-disease-specific sleep scales, ie, the Pittsburgh Sleep Quality Index and/or the Epworth Sleep Scale, although neither has been tested for reliability or validity in people with COPD.

Conclusion: The results highlight a need for existing non-disease-specific instruments to be validated in COPD populations and also a need for new disease-specific measures to assess the impact of sleep problems in COPD.

Keywords: sleep, symptom assessment, chronic obstructive pulmonary disease, systematic review

\section{Introduction}

Sleep problems are a common and important, but poorly understood and underresearched, aspect of chronic obstructive pulmonary disease (COPD). After breathlessness and fatigue, sleep disturbance is considered to be the third most common symptom experienced by people with respiratory disease ${ }^{1}$ and is also predictive of exacerbations, respiratory-related emergency hospital visits, and all-cause mortality. ${ }^{2}$ Insomnia describes any reported difficulty a person has with sleep ${ }^{3}$ and has four elements: difficulties falling asleep, interrupted sleep, trouble staying asleep, and still feeling tired and worn out even after a usual amount of sleep. ${ }^{3-5}$ Around $10 \%$ of the adult population is affected by insomnia, but the occurrence is much higher in 
people with COPD, where estimates range between $16 \%$ and $75 \% .^{6}$ The benefits of sleep are well known, and long-term interruption of normal sleeping patterns has a detrimental impact on physical, emotional, and social functioning, and is also associated with anxiety, depression, bodily pain, and a wide variety of pre-existing chronic medical conditions. ${ }^{4}$ In addition to insomnia, narcolepsy (suddenly falling asleep at inappropriate times), restless legs syndrome, and obstructive sleep apnea are the most common sleep disorders found in the general population, ${ }^{6}$ and people with COPD are disproportionately affected. Restless legs syndrome involves a need to move the legs, usually at night-time, is associated with marked sleep disturbance, and affects 7\%-14\% of the general population and $29 \%$ of patients with COPD. ${ }^{7,8}$ Obstructive sleep apnea is the periodic interruption of airflow in the upper airway during sleep and affects $3 \%-7 \%$ of the general population ${ }^{9}$ and $25 \%-29 \%$ of people with COPD. ${ }^{10}$ A summary of the occurrence of four common sleep disorders in COPD populations is provided in Table $1 .^{8,11-13}$

Given the importance of sleep disorders in COPD, being able to accurately classify their nature and severity is important in the management of COPD. Although self-reported sleep disorders are associated with COPD symptoms and poorer health-related quality of life, ${ }^{14}$ their relationship with traditional diagnostic markers of lung function (such as forced expiratory volume in one second, forced vital capacity, and oxygen saturation) is weak. ${ }^{15}$ This emphasizes the need for clinical instruments to accurately assess the impact of the disease and its treatment on a patient's health and well-being through patient-reported outcome measures (PROMs) ${ }^{16,17}$ as well as recording changes in physiological function.

Many of the instruments that have measured sleep disturbance in epidemiological studies were originally developed for people with a range of psychological conditions and/or pre-existing sleeping disorders. ${ }^{18,19}$ However, the validity of these measures cannot be assumed to transfer between clinical populations. ${ }^{19}$ Thus, the aim of this review was to identify

Table I Summary of the occurrence of common sleep disorders in COPD populations

\begin{tabular}{lll}
\hline Sleep disorder & Author & $\begin{array}{l}\text { Occurrence } \\
\text { in COPD }\end{array}$ \\
\hline $\begin{array}{l}\text { Insomnia (chronic sleep } \\
\text { disturbance with impaired } \\
\text { daytime functioning) }\end{array}$ & Budhiraja et al ${ }^{11}$ & $27 \%$ \\
$\begin{array}{l}\text { Excessive sleepiness } \\
\text { Restless legs syndrome }\end{array}$ & Ali Zohal et al $^{12}$ & $35 \%$ \\
Obstructive sleep apnea $^{\text {Kaplan et al }}{ }^{8}$ & $29 \%$ \\
\hline
\end{tabular}

Abbreviation: COPD, chronic obstructive pulmonary disease. and evaluate the suitability of published measures of sleep disturbance for use in people with COPD in order to make recommendations for best practice for clinical and research purposes. Our objectives were to:

- Identify which patient-reported outcome sleep measures have been used in people with COPD

- Identify which instruments have been developed and validated specifically for people with COPD

- Summarize the evidence for reliability and validity of sleep instruments in COPD patients

- Examine associations with sleep disturbance recorded by sleep instruments used in clinical studies of COPD patients.

\section{Materials and methods}

Ethical approval was not needed to undertake this review, which was performed according to Preferred Reporting Items for Systematic Reviews and Meta-Analyses guidelines. ${ }^{20}$

\section{Search strategy}

In this study, we conducted a systematic computerized literature review designed to identify all PROMs concerned with sleep problems experienced by people with COPD. The search included all instruments that had been developed and validated in people with COPD as well as generic instruments that had been developed for use in other disease areas and then administered to adult COPD patients.

\section{Stage I: Identification of sleep outcome measures used in COPD}

The first stage of the search was to identify sleep outcome measures that had been used in COPD. This was conducted using EMBASE, MEDLINE, and PsycINFO electronic databases for all years up to May 2014 using both key words, ie, the Medical Subject Headings (MeSH) "COPD” AND "sleep" and expanded to include all recognized subheadings. All titles, abstracts, and full texts from the identified papers were examined by the lead author (APG) for reference to specific sleep instruments or data indicating that at least one sleep outcome measure had been used. A list of sleep outcome measures was then produced. The reference lists and citations of selected articles were also searched to identify any additional sleep PROMs not found by the electronic database search.

\section{Stage 2: Selection and evaluation of sleep instruments used in COPD}

A SCOPUS database search was carried out on each of the detected sleep outcome measures to identify all publications 
in which the original paper had been cited. The search included the following related terms:

1. Construct-related terms: sleep problems

2. Population terms: COPD patients (in the title, abstract, text, or reference section)

3. Outcome-related terms: development, validation, or psychometric properties of sleep PROMs designed specifically for people with COPD. Sleep outcome measures not specifically designed for people with COPD but used in a COPD patient group whether psychometric data were reported or not

4. Method-related terms: instrument* OR measure* OR question* OR scale OR assess

5. Quality assessment terms: valid* or reliab* or evaluat* OR psychometric.

We also screened the reference lists and citations of included articles to identify additional relevant publications.

\section{Eligibility criteria}

To be included in the review, all identified articles had to meet the following inclusion criteria: the article described PROMs that either had been specifically designed and validated for use in patients with COPD or included a generic instrument that had been administered to COPD patients; information on at least one measurement property of the outcome measure was reported; the study sample consisted of adults with a clinical diagnosis of COPD; a full text of the original publication was published electronically, in English, in a peer-reviewed journal.

Articles were excluded if reference to COPD and/or sleep only appeared in the text or reference section. Similarly, we excluded all articles with mixed study samples where the results from COPD patients were not reported separately. Review articles, protocols, and case studies were also excluded. Two investigators (APG and JY) read independently all titles, abstracts, and full texts of all the retrieved articles to determine which were eligible for review. Any disagreements were resolved at a consensus meeting.

\section{Methodological quality assessment}

The COSMIN (COnsensus-based Standards for the selection of health Measurement INstruments) checklist ${ }^{21}$ is a standardized tool for evaluating the methodological quality of PROMs. COSMIN checklists are used to evaluate the measurement properties of instruments in terms of their internal consistency, reliability, measurement error, content validity, structural validity, hypothesis testing, cross-cultural validity, criterion validity, and responsiveness to change. As it was anticipated that the number of PROMs that had been developed and validated for use in COPD populations was likely to be very small, rather than using the full COSMIN checklist we used four PROM characteristics recommended by the US Food and Drug Administration ${ }^{22}$ to evaluate the measurement properties of identified sleep PROM instruments in relation to their use in COPD patients, ie, conceptual and measurement model, reliability, validity, and responsiveness to change.

\section{Conceptual model}

Identified articles were examined for descriptions of concepts contained within the instrument, including the rationale and process for deriving scale scores from raw scores, identifying and dealing with floor and ceiling effects, and scale variability.

\section{Reliability}

Articles were scrutinized for estimates of reliability, including inter-item correlations, test-retest repeatability, internal consistency, and/or kappa statistics.

\section{Validity}

Any reference to content, construct, and criterion-related validity were noted. When considering construct validity, we also recorded methods to differentiate between people with different levels of lung function or disease severity, such as the Global Initiative for Chronic Obstructive Lung Disease staging system that classifies people with COPD according to the results of pulmonary tests. Where available, we also collected data regarding the relationships between sleep outcome instruments and other established COPD outcome measures (such as the St George's Respiratory Questionnaire, ${ }^{23}$ the Medical Research Council Dyspnea scale, ${ }^{24}$ and routine clinical tests). Any analyses intended to examine dimensionality using factor analysis or Rasch analysis were noted, along with any assessments of differential item functioning that evaluated group differences in PROM item responses.

\section{Responsiveness to change}

All data relating to the ability of the instrument to detect changes over time in terms of sleep disturbance were noted. Where correlations between changes in scores of two measures are reported, these had to relate to predefined hypotheses.

\section{Results}

The stage 1 database search identified articles referring to COPD and sleep (Medline 804, EMBASE 2,314, and 
Table 2 Number of papers found and excluded or included in the review

\begin{tabular}{|c|c|c|c|c|}
\hline Outcome measures & SCOPUS references (n) & References to COPD (n) & Excluded & Reviewed \\
\hline COPD and Asthma Sleep Impact Scale ${ }^{25}$ & 8 & 6 & 5 & I \\
\hline Basic Nordic Sleep Questionnaire ${ }^{26}$ & 200 & 6 & 5 & I \\
\hline Berlin Questionnaire ${ }^{27}$ & 720 & 22 & 21 & I \\
\hline Epworth Sleepiness Scale ${ }^{28}$ & 4,720 & 153 & 133 & 20 \\
\hline International Restless Legs Syndrome ${ }^{29}$ & 548 & 4 & 3 & I \\
\hline Pittsburgh Sleep Quality Index ${ }^{30}$ & 4,144 & 71 & 52 & 19 \\
\hline Sleep Disorders Questionnaire ${ }^{31}$ & 262 & 8 & 7 & I \\
\hline Total & 10,602 & 270 & 226 & 44 \\
\hline
\end{tabular}

Abbreviation: COPD, chronic obstructive pulmonary disease.

PsycINFO 59) from which one COPD-specific and six non-disease-specific sleep instruments were identified (Table 2). ${ }^{25-31}$ In stage 2, the SCOPUS search found 10,602 articles citing any of the seven sleep outcome measures, 270 of which referred to COPD. After applying the exclusion criteria, 44 manuscripts were selected for review (Figure 1). Nearly $90 \%$ of the reviewed publications either used the Pittsburgh Sleep Quality Index (PSQI; ${ }^{30} 19 / 44,43.1 \%$ ) or the Epworth Sleepiness Scale (ESS; 20/44, 45.5\%). ${ }^{28}$ The 19-item PSQI measures sleep quality in seven domains and

Stage 1 Seven sleep instruments identified
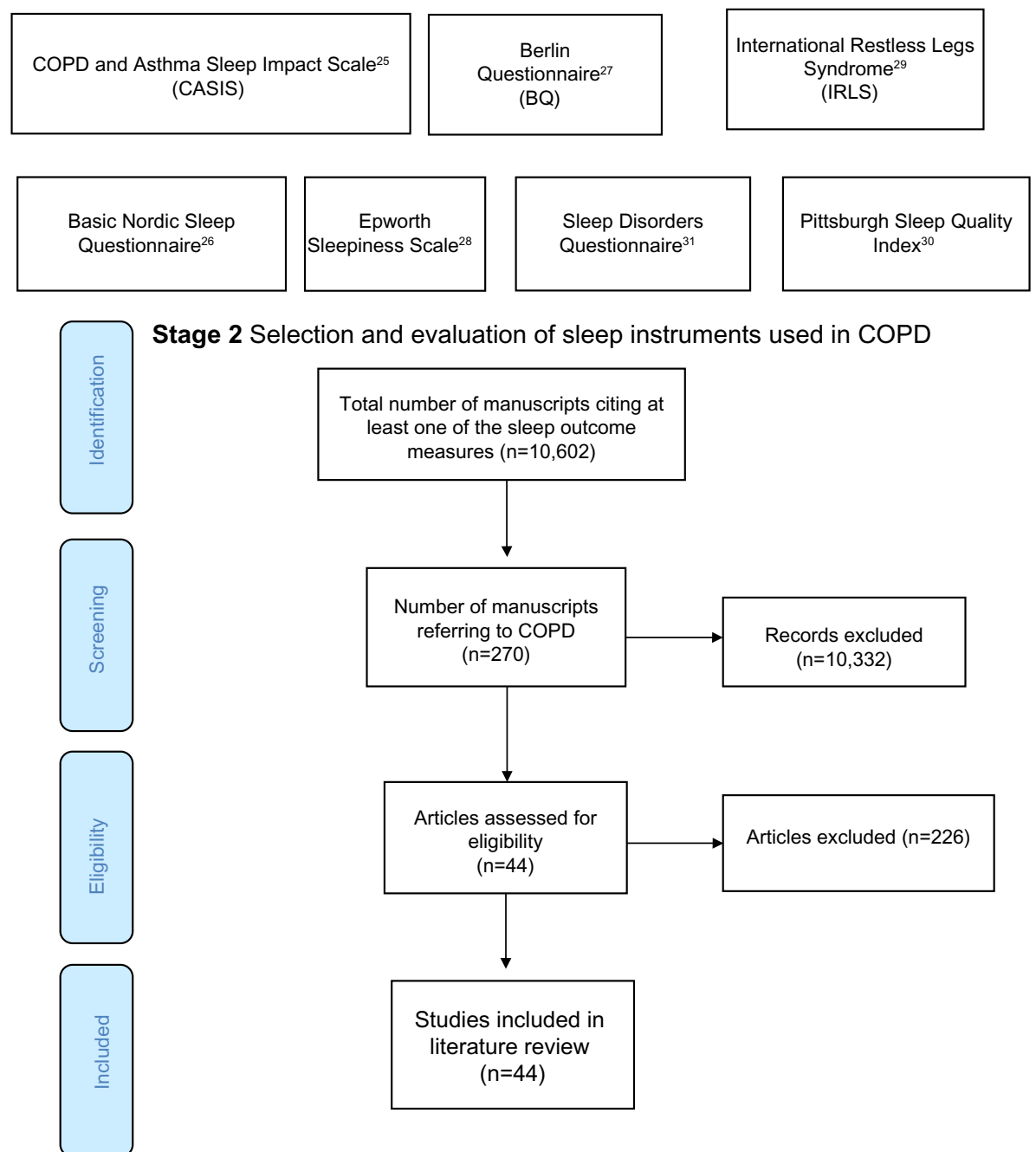

Figure I Flow diagram showing the total number of studies screened, assessed for eligibility and included in the review. Abbreviation: COPD, chronic obstructive pulmonary disease. 
the ESS assesses the likelihood of a person dozing off or falling asleep in eight common life situations. Most studies involved patients with moderate-severe COPD recruited from hospital outpatient or specialist respiratory clinics.

\section{COPD-specific sleep outcome measures}

After assessing the methodological properties of the identified PROMs, only one instrument appeared to have been developed and validated for use in COPD patients, ie, the COPD and Asthma Sleep Impact Scale (CASIS). ${ }^{25}$

The CASIS is a seven-item measure of sleep impairment during the previous week. Five items relate to disturbance falling asleep or staying awake during the day. The remaining two items concern sleep quality. The items are scored on a five-point scale ranging from 0 if the item never applies, to 4 if the item applies very often. A total raw score is produced from the sum of the seven individual scores which is then linearly transformed to a 0-100 total scale score. A mean CASIS score of $43.3 \pm 24.7$ was reported in patients with mild COPD. The results of the original psychometric testing of the CASIS (Table 3), showed that the scale had good internal consistency (Cronbach's alpha 0.91), test-retest reproducibility (intraclass coefficient 0.84 ), and concurrent validity (correlated with the St George's Respiratory Questionnaire, $r=0.68$ ).

Table 3 Psychometric properties of COPD and Asthma Sleep Impact Scale

\begin{tabular}{|c|c|}
\hline \multicolumn{2}{|c|}{ Conceptual and measurement model } \\
\hline $\begin{array}{l}\text { Rationale for deriving } \\
\text { scale scores }\end{array}$ & $\begin{array}{l}\text { Items generated from focus group discussions } \\
\text { in UK and US samples }\end{array}$ \\
\hline Scale structure & $\begin{array}{l}\text { I } 5 \text { item scale scored } \mathrm{I}=\text { never to } 5=\text { very } \\
\text { often }- \text { transferred onto a } 0-100 \text { scale }\end{array}$ \\
\hline Variability & Mean score COPD patients $(n=I 12) 47.1 \pm 24.0$ \\
\hline \multicolumn{2}{|l|}{ Reliability } \\
\hline $\begin{array}{l}\text { Inter-intra observer } \\
\text { repeatability }\end{array}$ & Not tested \\
\hline Item correlations & $\begin{array}{l}9 \text { items highly correlated } r>0.75 ; 6 \text { items } \\
\text { indicating item redundancy }\end{array}$ \\
\hline Internal consistency & Cronbach's alpha 0.91 \\
\hline Stability over time & 2-week test-retest repeatability ICC 0.84 \\
\hline \multicolumn{2}{|l|}{ Validity } \\
\hline \multirow[t]{3}{*}{ Convergent validity } & Correlated with SGRQ $r=0.68 P=0.0001$ \\
\hline & $\begin{array}{l}\text { Correlations between CASIS scores and } \\
\text { number of bad days } r=0.6 \mathrm{I} \text {, overall health } \\
\text { status ( } 0.5) \text {, and higher mean CASIS scores in } \\
\text { COPD patients receiving oxygen treatment } \\
(51.4 \text { vs } 43.3)\end{array}$ \\
\hline & $\begin{array}{l}\text { Correlates with living with COPD } \\
\text { questionnaire } 0.58\end{array}$ \\
\hline $\begin{array}{l}\text { Responsiveness } \\
\text { to change }\end{array}$ & Not tested \\
\hline
\end{tabular}

Abbreviations: COPD, chronic obstructive pulmonary disease; CASIS, COPD and Asthma Sleep Impact Scale; ICC, intra-class correlation coefficient; SGRQ, St George's Respiratory Questionnaire.
None of the non-disease-specific sleep scales reported any tests of reliability or validity to justify their use in the COPD population. Significant associations were observed in only $8 / 20(40 \%)$ of studies where the ESS was compared with other COPD-related outcome measures. For example, the prevalence of daytime sleepiness (ESS >10) was significantly greater in patients diagnosed with insomnia. ${ }^{11}$ Compared with people who had obstructive sleep apnea/ hypopnea syndrome, COPD patients were more likely to be affected by daytime sleepiness. ${ }^{32}$ Significant differences in mean ESS scores were observed between patients with COPD and restless legs syndrome compared with controls who had restless legs syndrome. ${ }^{33}$ However, no differences in daytime sleepiness were observed in a study that compared use of temazepam between COPD patients and controls. ${ }^{34}$ Similarly, no significant differences in ESS scores were detected in patients with and without restless legs syndrome ${ }^{35}$ (Table 4).

For the PSQI, significant associations were noted in $11 / 19(57.9 \%)$ of the relevant studies. PSQI scores were found to be significantly higher in patients with restless legs syndrome. ${ }^{36}$ PSQI total scores also correlated with total scores from the St George's Respiratory Questionnaire ${ }^{37,14}$ and the Fatigue Severity Scale. ${ }^{35}$ In contrast, no correlation was observed between PSQI and St George's Respiratory Questionnaire scores in an investigation of factors affecting health status in COPD patients with comorbid anxiety or depression. ${ }^{38}$ Further, although significant PSQI score reductions were observed in patients receiving a course of cognitive behavioral therapy (where the primary outcome was insomnia), ${ }^{39}$ no reductions in pre- and post-sleep quality were observed in a randomized controlled trial that compared cognitive behavioral therapy with usual care, where sleep was a secondary outcome measure to anxiety and depres$\operatorname{sion}^{40}$ (Table 5).

Table 6 shows the papers that used the four remaining generic outcome measures in studies of COPD patients. ${ }^{33,35,41,42}$ With so few studies, there are currently insufficient data to evaluate the utility of these instruments; however, in one study, ${ }^{33}$ International Restless Leg Study Group scores correlated significantly with ESS scores.

Although the results provide some evidence of the validity of measures of sleep disturbance in people with COPD, none of the above sleep measures were specifically evaluated for people with COPD. Similarly, we did not find any articles that provided data on test-retest, intrarater, or inter-rater reliability or responsiveness to change among COPD patient groups. 


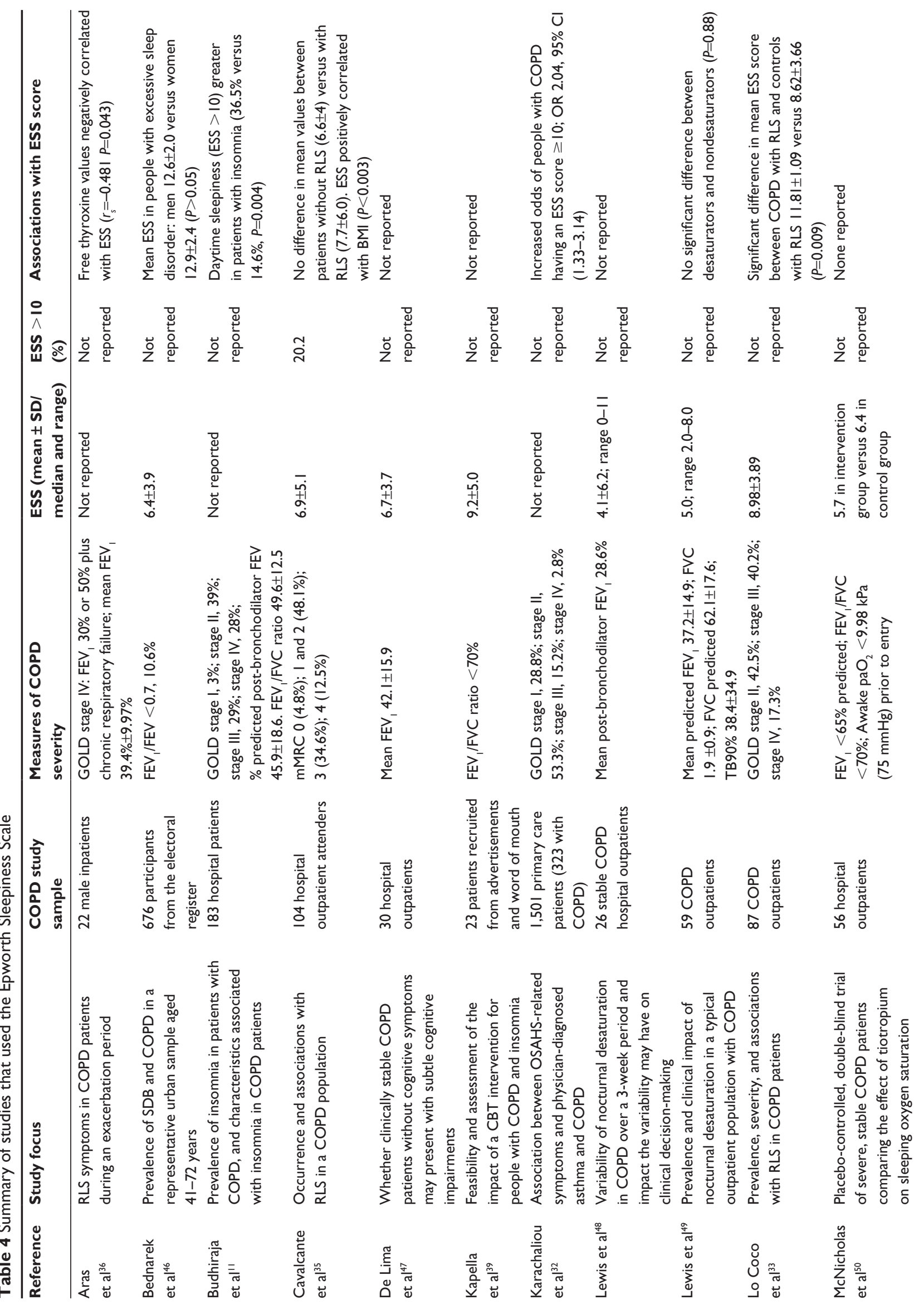




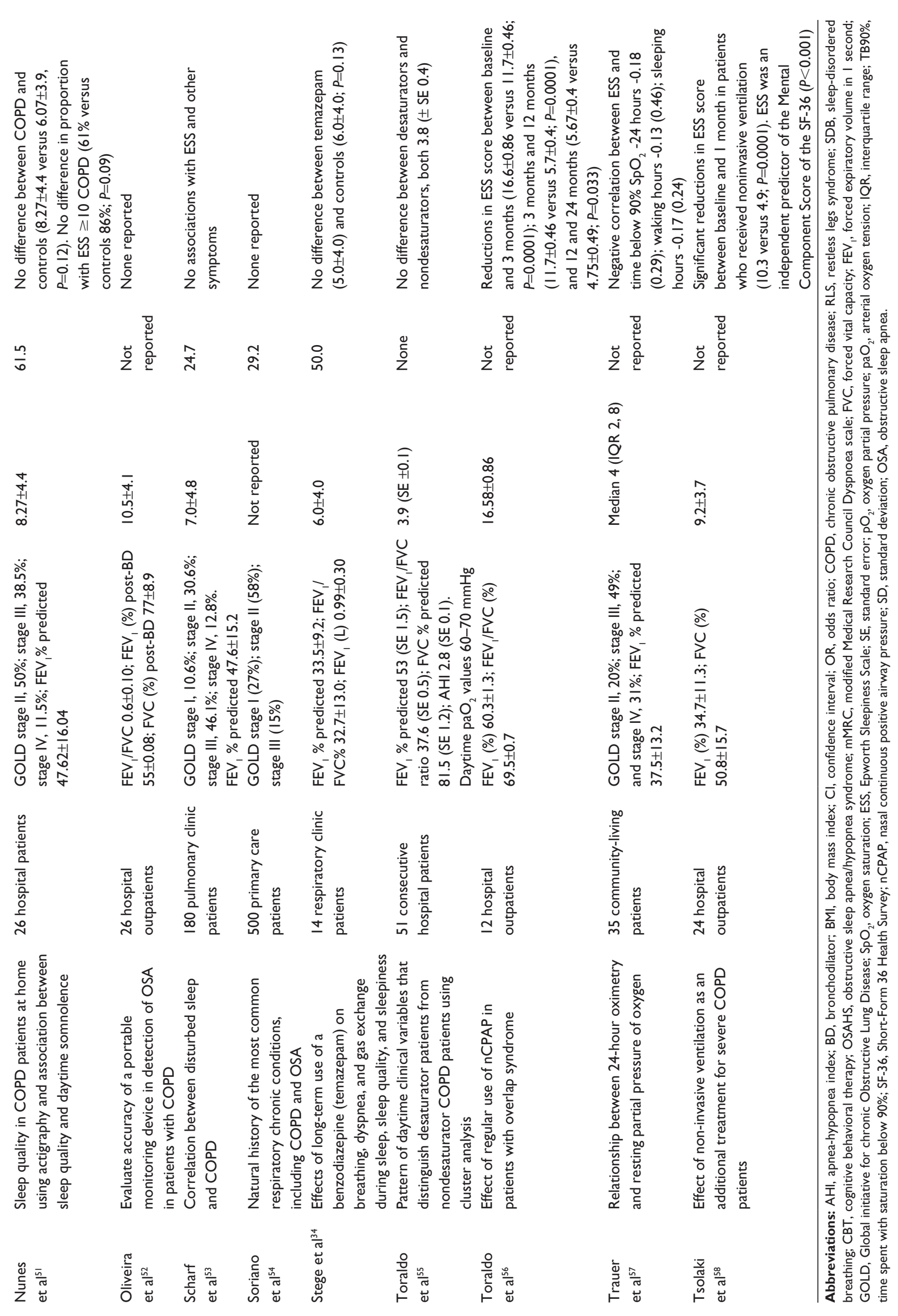




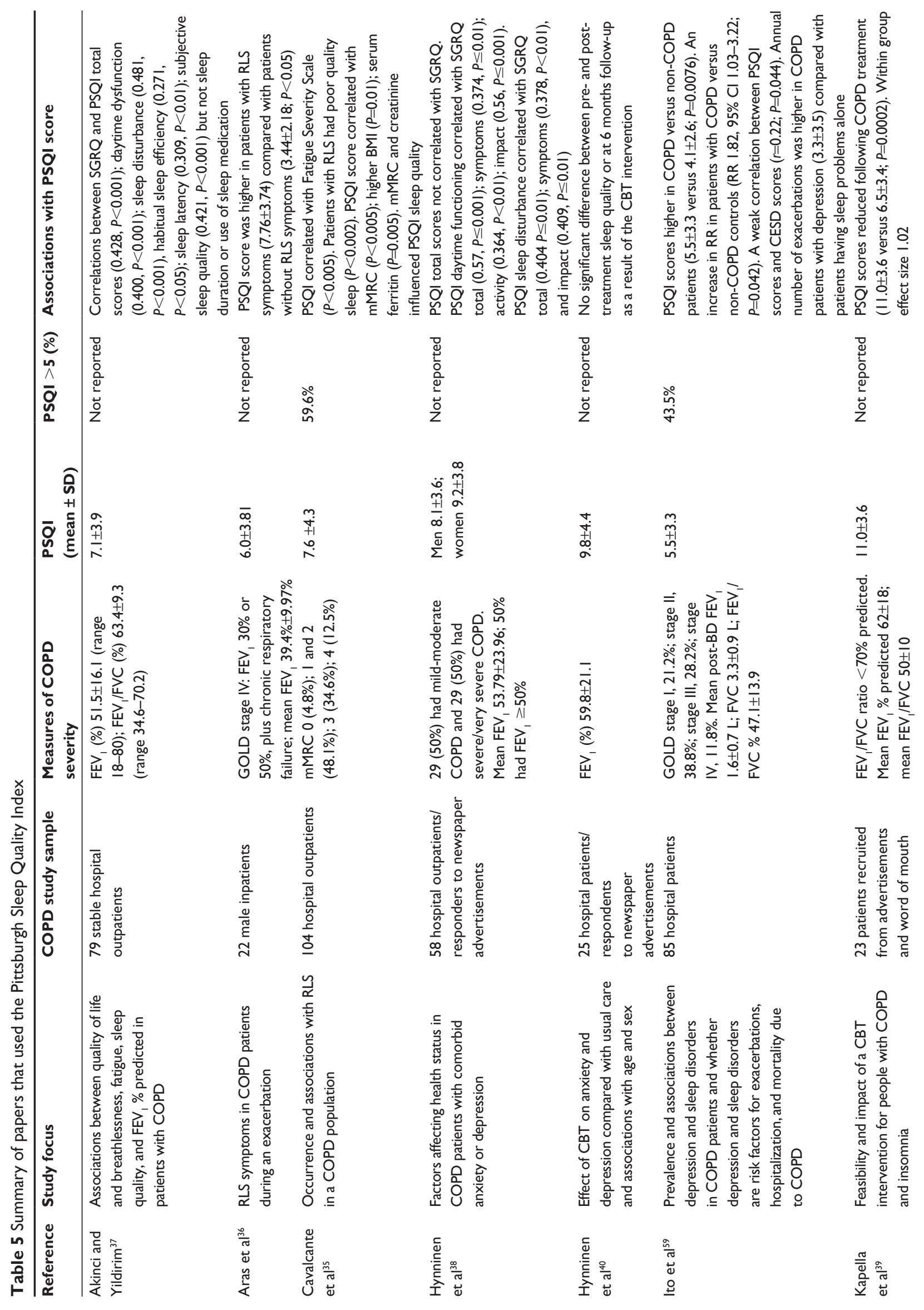



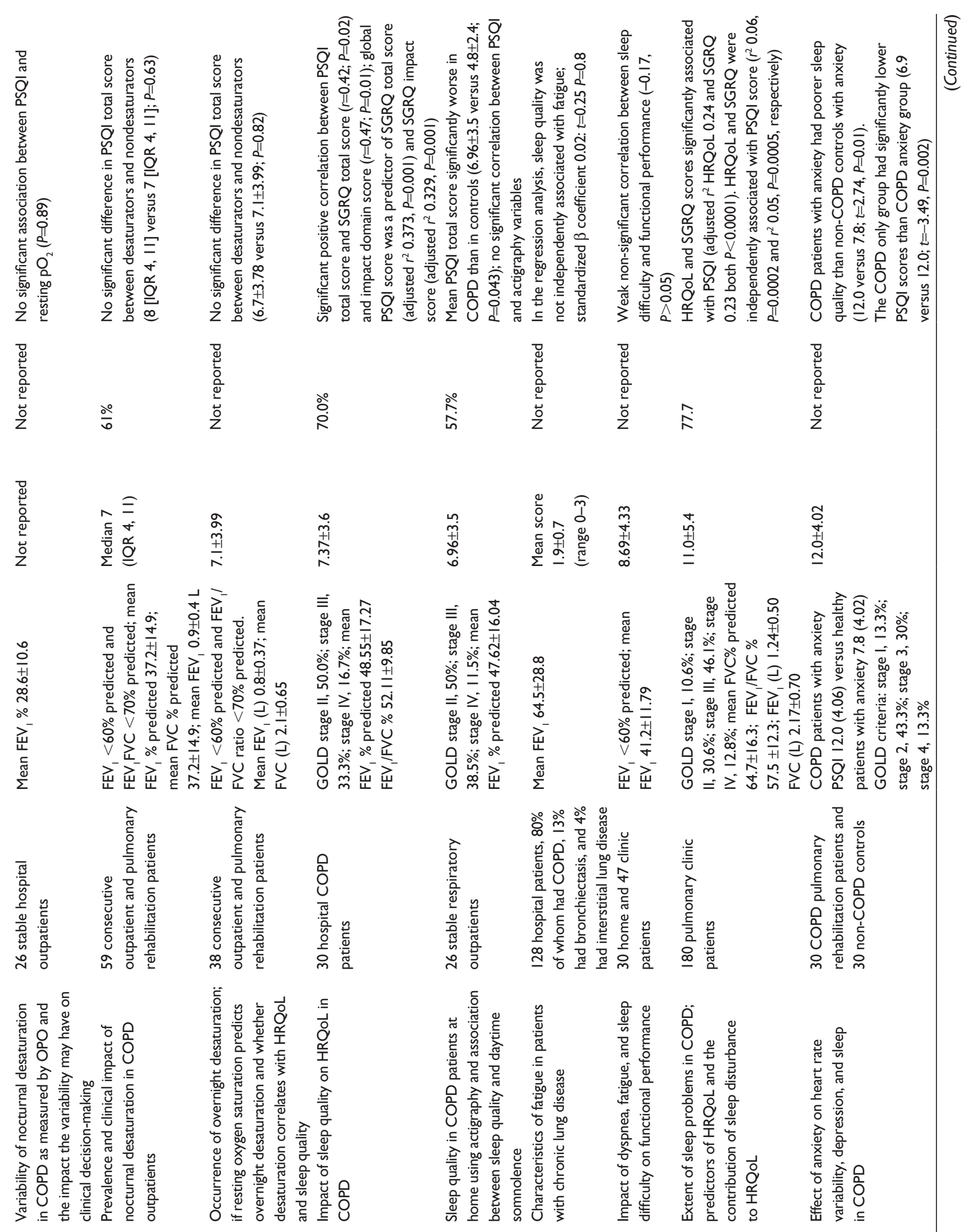

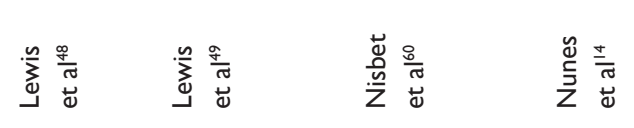

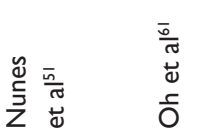
譬
$\frac{\pi}{\pi}$
$\frac{0}{5}$
$\frac{5}{5}$ 


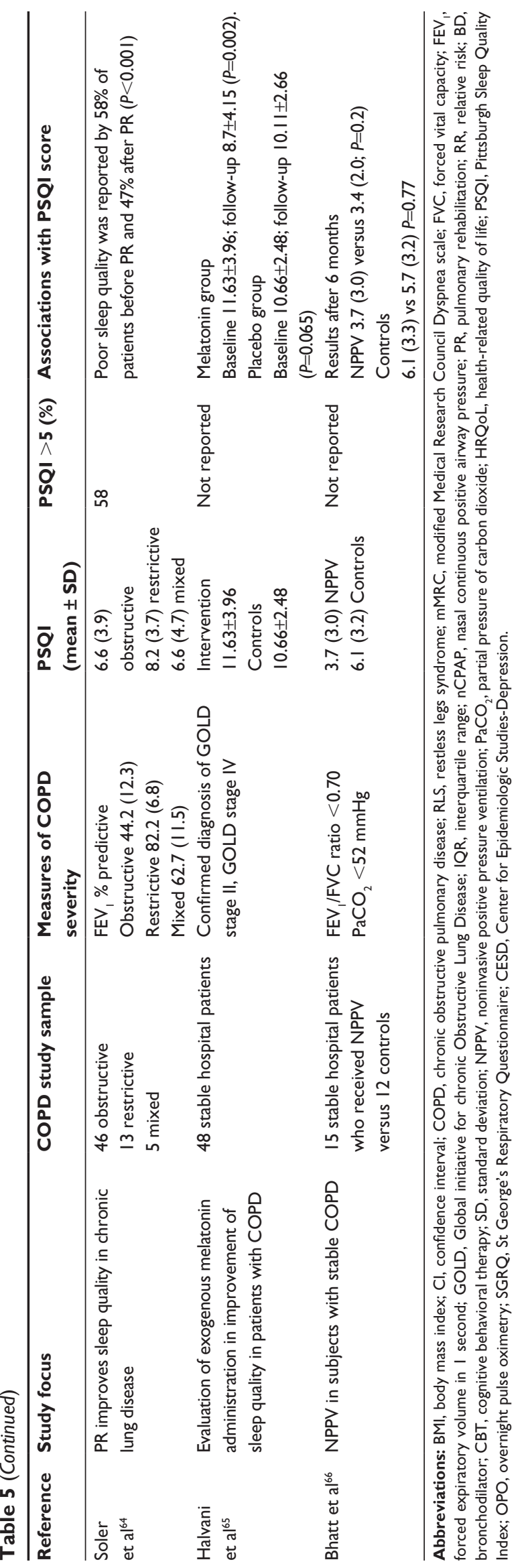

The point estimates of sleep disturbance from clinical studies of COPD patients using the ESS and the PSQI are shown on Tables 4 and 5. In 13/15 of the studies using the ESS, the mean/median scores were less than 10 , ie, below the accepted cutoff value for excessive daytime sleepiness. ${ }^{28}$ Most of the observed PSQI scores were above 5, ie, above the cutoff value representing poor quality sleep. ${ }^{30}$ Point and upper and lower quartile estimates for the ESS and PSQI are displayed on Figures 2 and 3.

\section{Discussion}

Sleep disturbances are an important problem that can seriously impact on physical and mental well-being as well as quality of life for people with COPD. This review identified seven outcome measures that have been used in COPD populations but none has been sufficiently validated to satisfy US Food and Drug Administration requirements to support labeling claims in medical product development. Only one measure, the CASIS, included item response theory modeling when evaluating the psychometric evaluation of the instrument. Incorporating item response theory is now considered to be an essential component in the design and validation of all PROMs. ${ }^{19}$

The majority of sleep studies in COPD have relied on two general measures of sleep dysfunction, the ESS and the PSQI, and although both of these instruments have been extensively used in a variety of clinical populations, neither has been validated for use in COPD patients.

As far as we are aware, this is the first systematic review of sleep measures in COPD. A strength of this study was the comprehensiveness of our literature search. We believe that we have identified all of the main PROMs of sleep disorders that have been used in COPD populations. Nevertheless, as we did not search all electronic databases or carry out a hand search, there is the possibility that we may have missed some relevant articles, particularly those that appeared in non-English language journals. However, by cross-checking the reference lists of all included papers and that of a recent systematic review of instruments designed to measure sleep dysfunction in adults, ${ }^{15}$ we believe we have minimized the loss of any important papers.

The review identified only one PROM, ie, the CASIS, which has been specifically designed and validated for use in COPD patients. In each item of the CASIS, patients are advised to "[...] think about the impact of breathing problems/ $\mathrm{COPD} /$ asthma on your sleep during the past week [...]" Most items, however, are general in nature and relate to the frequency of symptoms such as falling asleep, staying awake, and 


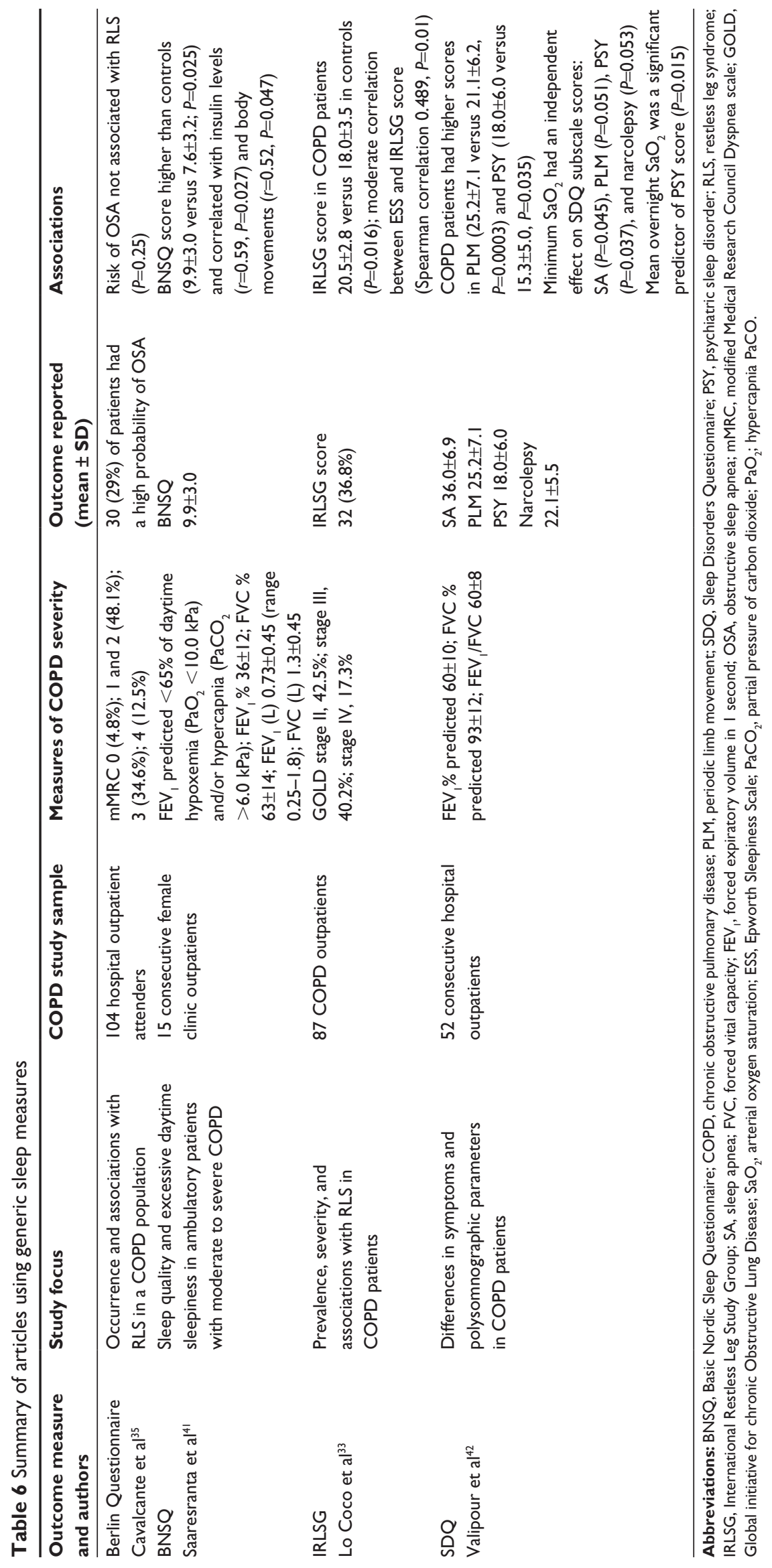




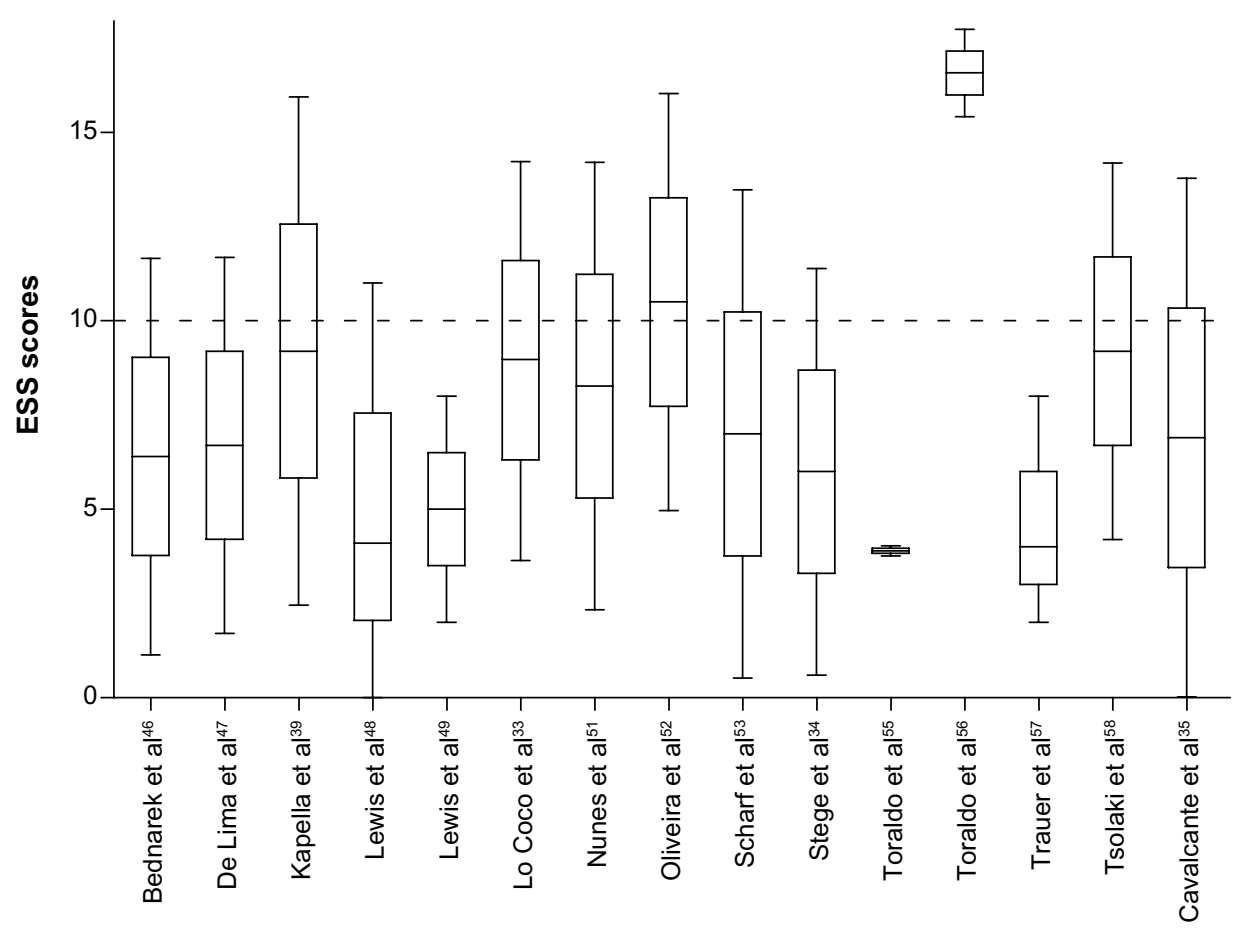

ESS $\geq 10=$ cut-off score for excessive sleepiness

Figure 2 Point estimates and variability in studies that used the ESS.

Abbreviation: ESS, Epworth Sleepiness Scale.

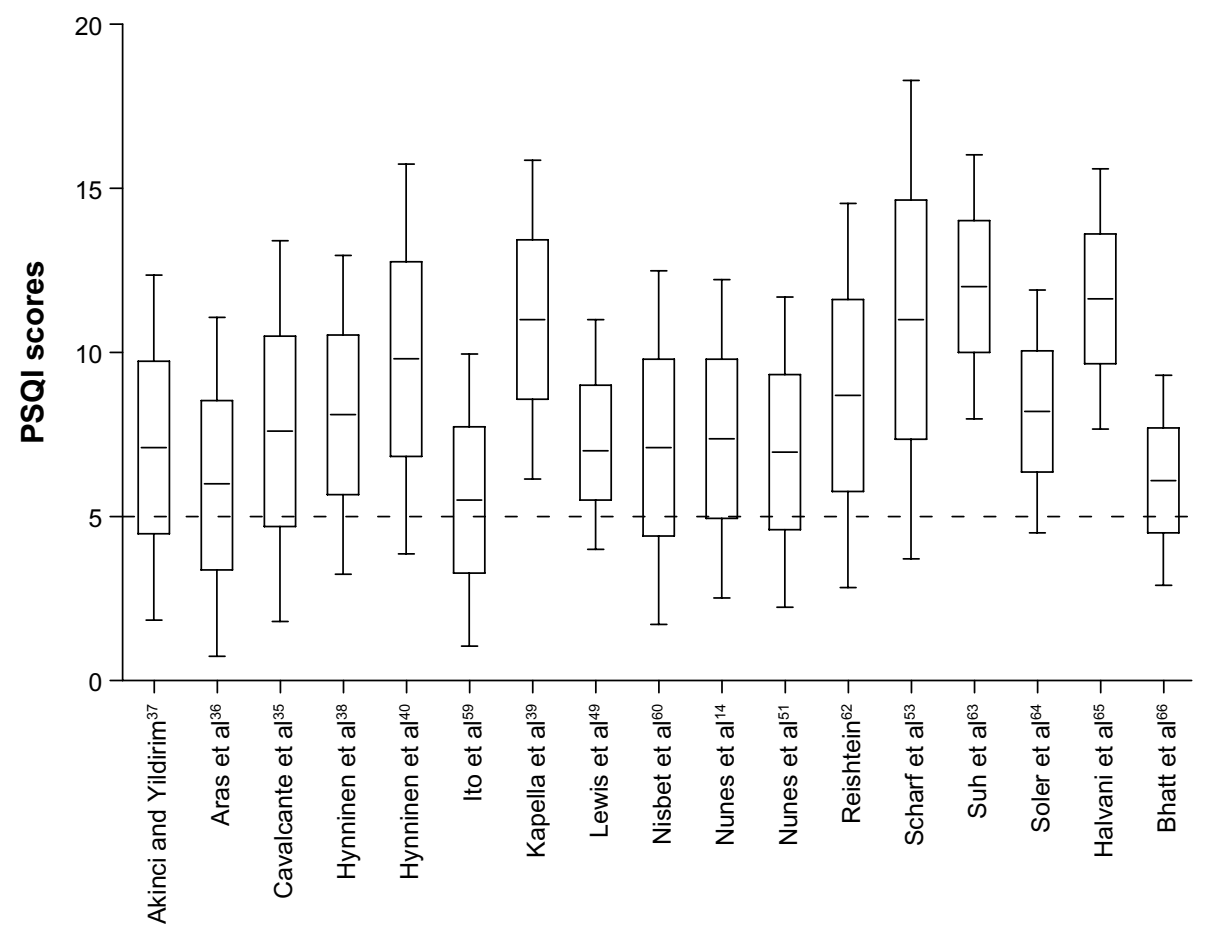

PSQI total score $\geq 5=$ indicator of poor sleep quality

Figure 3 Point estimates and variability in studies that used the PSQI.

Abbreviation: PSQI, Pittsburgh Sleep Quality Index. 
waking up feeling rested. Only one item relates specifically to breathing problems, ie, shortness of breath, coughing, and chest tightness. Further, as these symptoms are all contained within the same item, it is not possible to differentiate patients who may have different severity of symptoms; for example, between patients who wake up at night only with shortness of breath or wake up with both shortness of breath and coughing. Since the publication of the original paper, the CASIS has not been used in any intervention studies, so further evidence is needed to confirm the utility of this instrument in guiding the clinical management of COPD patients and in research.

This review has highlighted the current reliance of sleep research on generic sleep measures and the paucity of diseasespecific instruments currently available to assess the patient's experience of sleep in relation to COPD. By definition, generic measures tend to cover broad aspects such as functional status and perceptions and are more likely to identify aspects that are not disease-related. Because instruments validated in one population may not perform well in specific populations under investigation, separate validation of generic measures in each population is recommended..$^{43}$ Similarly, given that diseasespecific measures are generally more responsive to change, outcomes based solely on generic measures are unlikely to detect treatment-related improvements. ${ }^{44}$ These deficiencies could call into question findings from previous research on the impact of sleep problems in COPD. The need for validated COPD-specific sleep outcome measures was emphasized in an expert panel meeting held in $2011 .{ }^{45}$ While appreciating the multifactorial nature of sleep disturbance in COPD, the panel highlighted the need for an instrument to classify patients according to their night or daytime symptoms, which is not possible using existing PROMs for sleep. Development work on new COPD sleep PROMs to address these limitations is currently being carried out by the authors of this review.

\section{Conclusion}

This review highlights the complexity of sleep assessment, the inadequacy of non-disease-specific measures to capture problems experienced by people with COPD, and the absence of robust and validated methods of assessing and classifying symptoms associated with disrupted sleep in COPD. In studies using non-disease-specific sleep measures, there is a pressing need for these to be validated with COPD populations and/or for new disease-specific PROMs to be developed.

\section{Acknowledgment}

This partnership received financial support from the Knowledge Transfer Partnerships (KTP) program. The project was also supported by the UK Medical Research Council. KTP aims to help businesses to improve their competitiveness and productivity through the better use of knowledge, technology, and skills that reside within the UK knowledge base. KTP is funded by the Technology Strategy Board along with other government funding organizations.

\section{Author contributions}

All authors contributed to the design of the review. APG carried out the literature searches, produced draft manuscripts for review, and edited the manuscript prior to submission. JY read and verified the suitability of the articles for review and also participated in consensus meetings. ST provided guidance and editorial support during preparation of the review. All authors contributed and approved the final version of the manuscript. ST and JY are guarantors of the paper, taking responsibility for the integrity of the work as a whole from inception to the published article.

\section{Disclosure}

The authors report no conflicts of interest in this work.

\section{References}

1. Kinsman RA, Yaroush RA, Fernandez E, Dirks JF, Schocket M, Fukuhara J. Symptoms and experiences in chronic bronchitis and emphysema. Chest. 1983;83:755-761.

2. Omachi TA, Blanc PD, Claman DM, et al. Disturbed sleep among COPD patients is longitudinally associated with mortality and adverse COPD outcomes. Sleep Med. 2012;13:476-483.

3. National Institutes of Health. Information about sleep. 2013. Available from: http:/science.education.nih.gov/supplements/nih3/sleep/guide/ info-sleep.htm. Accessed July 9, 2013.

4. Morphy H, Dunn KM, Lewis M, Boardman HF, Croft PR. Epidemiology of insomnia: a longitudinal study in a UK population. Sleep. 2007;30: 274-280.

5. Leger D, Guilleminault C, Dreyfus JP, Delahaye C, Paillard M. Prevalence of insomnia in a survey of 12,778 adults in France. J Sleep Res. 2000;9:35-42.

6. Klink M, Quan SF. Prevalence of reported sleep disturbances in a general adult population and their relationship to obstructive airways diseases. Chest. 1987;91:540-546.

7. Allen RP, Earley CJ. Restless legs syndrome: a review of clinical and pathophysiologic features. J Clin Neurophysiol. 2001;18:128-147.

8. Kaplan Y, Inonu H, Yilmaz A, Ocal S. Restless legs syndrome in patients with chronic obstructive pulmonary disease. Can J Neurol Sci. 2008;35:352-357.

9. Punjabi NM. The epidemiology of adult obstructive sleep apnea. Proc Am Thorac Soc. 2008;5:136-143.

10. Jelic S. Diagnostic and therapeutic approach to coexistent chronic obstructive pulmonary disease and obstructive sleep apnea. Int J Chron Obstruct Pulmon Dis. 2008;3:269-275.

11. Budhiraja R, Parthasarathy S, Budhiraja P, Habib MP, Wendel C, Quan SF. Insomnia in patients with COPD. Sleep. 2012;35:369-375.

12. Ali Zohal M, Yazdi Z, Kazemifar AM. Daytime sleepiness and quality of sleep in patients with COPD compared to control group. Glob $\mathrm{J}$ Health Sci. 2013;5:150-155. 
13. McNicholas WT. Chronic obstructive pulmonary disease and obstructive sleep apnea: overlaps in pathophysiology, systemic inflammation, and cardiovascular disease. Am J Respir Crit Care Med. 2009;180:692-700.

14. Nunes DM, Mota RM, de Pontes Neto OL, Pereira ED, de Bruin VM, de Bruin PF. Impaired sleep reduces quality of life in chronic obstructive pulmonary disease. Lung. 2009;187:159-163.

15. Jones P, Miravitlles M, van der Molen T, Kulich K. Beyond FEV(1) in COPD: a review of patient-reported outcomes and their measurement. Int J Chron Obstruct Pulmon Dis. 2012;7:697-709.

16. National Health Service. Patient reported outcome measures: their role in measuring and improving patient experience. 2012. Available from: http://patientexperienceportal.org/article/patient-reported-outcomemeasures-their-role-in-measuring-and-improving-patient-experience. Accessed April 3, 2014.

17. Rothrock NE, Hays RD, Spritzer K, Yount SE, Riley W, Cella D. Relative to the general US population, chronic diseases are associated with poorer health-related quality of life as measured by the PatientReported Outcomes Measurement Information System (PROMIS). J Clin Epidemiol. 2010;63:1195-1204.

18. American Academy of Sleep Medicine. International classification of sleep disorders, revised: diagnostic and coding manual. Chicago, IL, USA: American Academy of Sleep Medicine; 2001. Available from: http://www.esst.org/adds/ICSD.pdf. Accessed April 4, 2014.

19. Devine EB, Hakim Z, Green J. A systematic review of patientreported outcome instruments measuring sleep dysfunction in adults. Pharmacoeconomics. 2005;23:889-912.

20. Moher D, Liberati A, Tetzlaff J, Altman DG; PRISMA Group. Preferred reporting items for systematic reviews and meta-analyses: the PRISMA statement. BMJ. 2009;339:b2535.

21. Mokkink LB, Terwee CB, Patrick DL, et al. International consensus on taxonomy, terminology, and definitions of measurement properties: results of the COSMIN study. J Clin Epidemiol. 2010;63:737-745.

22. US Department of Health and Human Services Food and Drug Administration. Guidance for industry: patient-reported outcome measures: use in medical product development to support labeling claims. 2009. Available from: http://www.fda.gov/downloads/Drugs/Guidances/ UCM193282.pdf. Accessed April 30, 2014.

23. Jones PW, Quirk FH, Baveystock CM. The St George's Respiratory Questionnaire. Respir Med. 1991;85 Suppl B:25-31.

24. Fletcher CM, Elmes PC, Fairbairn AS, Wood CH. The significance of respiratory symptoms and the diagnosis of chronic bronchitis in a working population. BMJ. 1959;2:257-266.

25. Pokrzywinski RF, Meads DM, McKenna SP, Glendenning GA, Revicki DA. Development and psychometric assessment of the COPD and Asthma Sleep Impact Scale (CASIS). Health Qual Life Outcomes. 2009;7:98.

26. Partinen M, Gislason T. Basic Nordic Sleep Questionnaire (BNSQ): a quantitated measure of subjective sleep complaints. J Sleep Res. 1995;4:150-155.

27. Netzer NC, Stoohs RA, Netzer CM, Clark K, Strohl KP. Using the Berlin Questionnaire to identify patients at risk for the sleep apnea syndrome. Ann Intern Med. 1999;131:485-491.

28. Johns MW. A new method for measuring daytime sleepiness: the Epworth sleepiness scale. Sleep. 1991;14:540-545.

29. Walters AS, LeBrocq C, Dhar A, et al; International Restless Legs Syndrome Study Group. Validation of the International Restless Legs Syndrome Study Group rating scale for restless legs syndrome. Sleep Med. 2003;4:121-132.

30. Buysse DJ, Reynolds CF 3rd, Monk TH, Berman SR, Kupfer DJ. The Pittsburgh Sleep Quality Index: a new instrument for psychiatric practice and research. Psychiatry Res. 1989;28:193-213.

31. Douglass AB, Bornstein R, Nino-Murcia G, et al. The Sleep Disorders Questionnaire. I: Creation and multivariate structure of SDQ. Sleep. 1994; 17:160-167.

32. Karachaliou F, Kostikas K, Pastaka C, Bagiatis V, Gourgoulianis KI. Prevalence of sleep-related symptoms in a primary care population - their relation to asthma and COPD. Prim Care Respir J. 2007;16: 222-228.
33. Lo Coco D, Mattaliano A, Coco AL, Randisi B. Increased frequency of restless legs syndrome in chronic obstructive pulmonary disease patients. Sleep Med. 2009;10:572-576.

34. Stege G, Heijdra YF, van den Elshout FJ, et al. Temazepam $10 \mathrm{mg}$ does not affect breathing and gas exchange in patients with severe normocapnic COPD. Respir Med. 2010;104:518-524.

35. Cavalcante AG, de Bruin PF, de Bruin VM, et al. Restless legs syndrome, sleep impairment, and fatigue in chronic obstructive pulmonary disease. Sleep Med. 2012;13:842-847.

36. Aras G, Kadakal F, Purisa S, Kanmaz D, Aynaci A, Isik E. Are we aware of restless legs syndrome in COPD patients who are in an exacerbation period? Frequency and probable factors related to underlying mechanism. COPD. 2011;8:437-443.

37. Akinci AC, Yildirim E. Factors affecting health status in patients with chronic obstructive pulmonary disease. Int J Nurs Pract. 2013;19: 31-38.

38. Hynninen MJ, Pallesen S, Nordhus IH. Factors affecting health status in COPD patients with co-morbid anxiety or depression. Int J Chron Obstruct Pulmon Dis. 2007;2:323-328.

39. Kapella MC, Herdegen JJ, Perlis ML, et al. Cognitive behavioral therapy for insomnia comorbid with COPD is feasible with preliminary evidence of positive sleep and fatigue effects. Int J Chron Obstruct Pulmon Dis. 2011;6:625-635.

40. Hynninen MJ, Bjerke N, Pallesen S, Bakke PS, Nordhus IH. A randomized controlled trial of cognitive behavioral therapy for anxiety and depression in COPD. Respir Med. 2010;104:986-994.

41. Saaresranta T, Irjala K, Aittokallio T, Polo O. Sleep quality, daytime sleepiness and fasting insulin levels in women with chronic obstructive pulmonary disease. Resp Med. 2005;99:856-863.

42. Valipour A, Lavie P, Lothaller H, Mikulic I, Burghuber OC. Sleep profile and symptoms of sleep disorders in patients with stable mild to moderate chronic obstructive pulmonary disease. Sleep Med. 2011;12:367-372.

43. Matza LS, Boye KS, Yurgin N. Validation of two generic patient-reported outcome measures in patients with type 2 diabetes. Health Qual Life Outcomes. 2007;5:47

44. Wiebe S, Guyatt G, Weaver B, Matijevic S, Sidwell C. Comparative responsiveness of generic and specific quality-of-life instruments. J Clin Epidemiol. 2003;56:52-60.

45. Agusti A, Hedner J, Marin JM, et al. Night-time symptoms: a forgotten dimension of COPD. Eur Respir Rev. 2011;20:183-194.

46. Bednarek M, Plywaczewski R, Jonczak L, Zielinski J. There is no relationship between chronic obstructive pulmonary disease and obstructive sleep apnea syndrome: a population study. Respiration. 2005;72:142-149.

47. De Lima OM, Oliveira-Souza Rd, Santos Oda R, Moraes PA, Sá LF, Nascimento OJ. Subclinical encephalopathy in chronic obstructive pulmonary disease. Arq Neuropsiquiatr. 2007;65:1154-1157.

48. Lewis CA, Eaton TE, Fergusson W, Whyte KF, Garrett JE, Kolbe J. Home overnight pulse oximetry in patients with COPD: more than one recording may be needed. Chest. 2003;123:1127-1133.

49. Lewis CA, Fergusson W, Eaton T, Zeng I, Kolbe J. Isolated nocturnal desaturation in COPD: prevalence and impact on quality of life and sleep. Thorax. 2009;64:133-138.

50. McNicholas WT, Calverley PM, Lee A, Edwards JC; Tiotropium Sleep Study in COPD Investigators. Long-acting inhaled anticholinergic therapy improves sleeping oxygen saturation in COPD. Eur Respir J. 2004;23:825-831.

51. Nunes DM, De Bruin VM, Louzada FM, et al. Actigraphic assessment of sleep in chronic obstructive pulmonary disease. Sleep Breath. $2013 ; 17: 125-132$.

52. Oliveira MG, Nery LE, Santos-Silva R, et al. Is portable monitoring accurate in the diagnosis of obstructive sleep apnea syndrome in chronic pulmonary obstructive disease? Sleep Med. 2012;13:1033-1038.

53. Scharf SM, Maimon N, Simon-Tuval T, Bernhard-Scharf BJ, Reuveni H, Tarasiuk A. Sleep quality predicts quality of life in chronic obstructive pulmonary disease. Int J Chron Obstruct Pulmon Dis. 2011;6:1-12.

54. Soriano JB, Yanez A, Renom F, et al. Set-up and pilot of a population cohort for the study of the natural history of COPD and OSA: the PULSAIB study. Prim Care Respir J. 2010;19:140-147. 
55. Toraldo DM, Nicolardi G, De Nuccio F, Lorenzo R, Ambrosino N Pattern of variables describing desaturator COPD patients, as revealed by cluster analysis. Chest. 2005;128:3828-3837.

56. Toraldo DM, De Nuccio F, Nicolardi G. Fixed-pressure nCPAP in patients with obstructive sleep apnea (OSA) syndrome and chronic obstructive pulmonary disease (COPD): a 24-month follow-up study. Sleep Breath. 2010;14:115-123.

57. Trauer JM, Gielen C, Trauer T, Steinfort CL. Inability of single resting arterial blood gas to predict significant hypoxaemia in chronic obstructive pulmonary disease. Intern Med J. 2012;42: 387-394.

58. Tsolaki V, Pastaka C, Karetsi E, et al. One-year non-invasive ventilation in chronic hypercapnic COPD: effect on quality of life. Respir Med. 2008;102:904-911.

59. Ito K, Kawayama T, Shoji Y, et al. Depression, but not sleep disorder, is an independent factor affecting exacerbations and hospitalization in patients with chronic obstructive pulmonary disease. Respirology. 2012;17:940-949.
60. Nisbet M, Eaton T, Lewis C, Fergusson W, Kolbe J. Overnight prescription of oxygen in long term oxygen therapy: time to reconsider the guidelines? Thorax. 2006;61:779-782.

61. Oh EG, Kim CJ, Lee WH, Kim SS. Correlates of fatigue in Koreans with chronic lung disease. Heart Lung. 2004;33:13-20.

62. Reishtein JL. Relationship between symptoms and functional performance in COPD. Res Nurs Health. 2005;28:39-47.

63. Suh S, Ellis RJ, Sollers JJ 3rd, Thayer JF, Yang HC, Emery CF. The effect of anxiety on heart rate variability, depression, and sleep in chronic obstructive pulmonary disease. J Psychosom Res. 2013;74:407-413.

64. Soler X, Diaz-Piedra C, Ries AL. Pulmonary rehabilitation improves sleep quality in chronic lung disease. COPD. 2013;10:156-163.

65. Halvani A, Mohsenpour F, Nasiriani K. Evaluation of exogenous melatonin administration in improvement of sleep quality in patients with chronic obstructive pulmonary disease. Tanaffos. 2013;12:9-15.

66. Bhatt SP, Peterson MW, Wilson JS, Durairaj L. Noninvasive positive pressure ventilation in subjects with stable COPD: a randomized trial. Int J Chron Obstruct Pulmon Dis. 2013;8:581-589.

\section{Publish your work in this journal}

The International Journal of COPD is an international, peer-reviewed journal of therapeutics and pharmacology focusing on concise rapid reporting of clinical studies and reviews in COPD. Special focus is given to the pathophysiological processes underlying the disease, intervention programs, patient focused education, and self management protocols.

\section{Dovepress}

This journal is indexed on PubMed Central, MedLine and CAS. The manuscript management system is completely online and includes a very quick and fair peer-review system, which is all easy to use. Visit http://www.dovepress.com/testimonials.php to read real quotes from published authors. 